\title{
Functionalization of different polymers with sulfonic groups as a way to coat them with a biomimetic apatite layer
}

\author{
I. B. Leonor · H. -M. Kim · F. Balas · M. Kawashita · \\ R. L. Reis - T. Kokubo - T. Nakamura
}

Received: 8 July 2005/Accepted: 5 July 2006/Published online: 7 June 2007

(C) Springer Science+Business Media, LLC 2007

\begin{abstract}
Covalent coupling of sulfonic group $\left(-\mathrm{SO}_{3} \mathrm{H}\right)$ was attempted on different polymers to evaluate efficacy of this functional group in inducing nucleation of apatite in body environment, and thereupon to design a simple biomimetic process for preparing bonelike apatite-polymer composites. Substrates of polyethylene terephthalate (PET), polycaprolactam (Nylon 6), high molecular weight polyethylene (HMWPE) and ethylene-vinyl alcohol copolymer $(\mathrm{EVOH})$ were subjected to sulfonation by being soaked in sulfuric acid $\left(\mathrm{H}_{2} \mathrm{SO}_{4}\right)$ or chlorosulfonic acid
\end{abstract}

I. B. Leonor $(\bowtie) \cdot$ R. L. Reis

3B's Research Group, Department of Polymer Engineering,

University of Minho, Campus de Gualtar, 4710-057 Braga,

Portugal

e-mail: belinha@dep.uminho.pt

I. B. Leonor · R. L. Reis

Department of Polymer Engineering, University of Minho,

Campus de Azurém, 4800-058 Guimaraes, Portugal

H. -M.Kim ( $\square)$

Department of Ceramic Engineering, School of Advanced Materials Engineering, Yonsei University, 134 Shinchon-dong, Seodaemun-gu, Seoul 120-749, Korea

e-mail: hmkim@yonsei.ac.kr

F. Balas · T. Kokubo

Research Institute for Science and Technology, Chubu

University, 1200 Matsumoto-cho, Kasugai-shi, Aichi 487-8501,

Japan

M. Kawashita

Ion Beam Engineering Experimental Laboratory, Graduate

School of Engineering, Kyoto University, Kyoto-Daigaku

Ktsura, Nishikyo-ku, Kyoto 615-8510, Japan

T. Nakamura

Department of Orthopaedic Surgery, Faculty of Medicine, Kyoto

University, Sakyo-ku, Kyoto 606-8506, Japan
$\left(\mathrm{ClSO}_{3} \mathrm{H}\right)$ with different concentrations. In order to incorporate calcium ions, the sulfonated substrates were soaked in saturated solution of calcium hydroxide $\left(\mathrm{Ca}(\mathrm{OH})_{2}\right)$. The treated substrates were soaked in a simulated body fluid (SBF). Fourier transformed infrared spectroscopy, thin-film X-ray diffraction, and scanning electron microscopy showed that the sulfonation and subsequent $\mathrm{Ca}(\mathrm{OH})_{2}$ treatments allowed formation of $-\mathrm{SO}_{3} \mathrm{H}$ groups binding $\mathrm{Ca}^{2+}$ ions on the surface of HMWPE and EVOH, but not on PET and Nylon 6. The HMWPE and EVOH could thus form bonelike apatite layer on their surfaces in SBF within $7 \mathrm{~d}$. These results indicate that the $-\mathrm{SO}_{3} \mathrm{H}$ groups are effective for inducing apatite nucleation, and thereby that surface sulfonation of polymers are effective pre-treatment method for preparing biomimetic apatite on their surfaces.

\section{Introduction}

Bioactive ceramics, such as Bioglass ${ }^{\circledR}[1]$, sintered hydroxyapatite (HA) [2, 3] and glass-ceramic A-W [4] are smart biomaterials that establish a biological integration with living bone after implantation in bone defect [5-7]. The bone-integration of bioactive ceramics is known to come off by formation of biologically active bone-like layer of apatite on the surfaces of ceramics $[8,9]$. There have been therefore a large number of in vitro and in vivo studies on the mechanism of surface chemistry of different bioactive ceramics concerning formation of the bone-like apatite [10-12]. In vitro studies in simulated body fluid indicate that the formation of apatite is heterogeneous nucleation and growth of apatite crystals from metastable supersaturated blood plasma or blood-plasma like solution 
such as simulated body fluid, which is induced by surface functional groups, such as $\mathrm{Si}-\mathrm{OH}$ and $\mathrm{Ti}-\mathrm{OH}$ groups specifically on the bioactive ceramics. These functional groups are speculated revealing a negative charge to trigger electrostatic interaction with the calcium and phosphate ions in the fluid, and thereby to form the apatite crystal [13-15]. This mechanism has been in fact very useful to design bioactive materials with different properties. For one example, bioactive titanium and titanium alloy has been developed by chemical treatments which produces functional groups of $\mathrm{Ti}-\mathrm{OH}$ in situ on the metal surface [16, 17]. For other example, synthetic polymers have been surface-treated to be induced apatite-forming ability by being coupled with functional groups of $\mathrm{Si}-\mathrm{OH}$, and to be coated with bone-like apatite $[18,19]$. This process has been termed biomimetic process, which is potential method to design 3-dimensional apatite-polymer composite for bone-like mechanical properties and graft applications.

In our current knowledge of functional groups able to induce apatite nucleation, which develop a negative charge on immersion in water can lead nucleation, meaning high acidity of functional group may be essential for apatite nucleation. For example, Himeno et al. [13, 14] confirmed these results by means of an electrophoresis study. They have shown that the surface potential by functional sites is initially negative, indicating that the initialization of apatite nucleation involves an electrostatic interaction between the functional sites and calcium ions. Therefore, functional groups able to become negatively charge at the blood plasma $\mathrm{pH}(\approx 7.4$.) are assumed to be potentially effective for the apatite nucleation in an in vivo environment. In terms of acidity, the sulfonic group $\left(-\mathrm{SO}_{3} \mathrm{H}\right)$ is worthy of research as nucleating agent of apatite. To incorporate $\mathrm{SO}_{3} \mathrm{H}$ groups onto biocompatible polymeric surfaces, it was used four types of polymers, PET, Nylon 6, HMWPE and EVOH, which are well known in the medical field [2024]. These polymeric materials have high chemical stability and both good mechanical properties and biocompatibility. Therefore, if $-\mathrm{SO}_{3} \mathrm{H}$ groups can be incorporated by covalent attachment on different polymeric surfaces it is possible to assess the assumption of this functional group as well as to develop bioactive surface in situ by functionalization. Such combination should allow for the development of bioactive apatite-polymer composites, with a bonelike 3-dimensional structure.

\section{Materials and methods}

\section{Preparation of polymer substrates}

Four types of polymer substrates were used in the present study: (i) polyethylene terephthalate (PET; Toyoboseki Co.
Ltd., Japan), (ii) polycaprolactam (Nylon 6; Scientific Polymer Products, Inc., Germany), (iii) high molecular weight polyethylene (HMWPE; Hostalen ${ }^{\circledR}$ GM 9255F, Hoechst, Germany), and (iv) ethylene-vinyl alcohol copolymer $(\mathrm{EVOH}$; Kuraray Co., Ltd., Japan; ethylene content $=32 \mathrm{~mol} \%$ ). PET, Nylon 6 and EVOH substrates were obtained by hot compression moulding in order to produce plates, which were cooled down with water out of the mould. HMWPE substrates were obtained by conventional injection moulding in a Klockner-Ferromatik Desma FM20 machine in order to produce plates. These plates were cut into substrate specimens with $10 \times 10 \times 1 \mathrm{~mm}^{3}$ in size. The substrates were abraded with No. 400 diamond paste, ultrasonically washed with distilled water, and dried at $40^{\circ} \mathrm{C}$ for $24 \mathrm{~h}$.

\section{Solution treatments of polymer substrates}

Two solutions were used for sulfonation of the polymer substrates: sulfuric acid $\left(95 \% \mathrm{H}_{2} \mathrm{SO}_{4}\right.$, Nacalai Tesque, Japan) and chlorosulfonic acid $\left(99 \% \mathrm{ClSO}_{3} \mathrm{H}\right.$, Aldrich, USA). They were conditioned to have different concentrations by being diluted respectively with distilled water and 1, 2-dichloroethane (ClCHCHCl, Aldrich, USA). The polymers were soaked in these solutions with different conditions of concentrations, temperatures and periods to study the appropriate conditions to treat the polymers without visibly severe corrosion. Table 1 lists these conditions for each polymer, at which the polymer substrates were soaked in $5 \mathrm{~mL}$ of $\mathrm{H}_{2} \mathrm{SO}_{4}$ or $\mathrm{ClSO}_{3} \mathrm{H}$ solutions in Teflon ${ }^{\circledR}$ tubes and shaken at 120 strokes/min.

With an assumption that the calcium ions together with $\mathrm{SO}_{3} \mathrm{H}$ groups might promote nucleation of apatite, the above sulfonated polymers were treated with calcium hydroxide $\left(\mathrm{Ca}(\mathrm{OH})_{2}\right)$ solution. Substrates after sulfonation were immediately soaked in $50 \mathrm{~mL}$ of saturated $(\sim 6.7 \mathrm{mM})$ $\mathrm{Ca}(\mathrm{OH})_{2}$ for $24 \mathrm{~h}$ at $40{ }^{\circ} \mathrm{C}$, and washed with distilled water.

Soaking in simulated body fluid (SBF)

Sulfonated and $\mathrm{Ca}(\mathrm{OH})_{2}$-treated substrates were soaked in a simulated body fluid (SBF) [25] with ion concentrations $\left(\mathrm{Na}^{+} 142.0, \mathrm{~K}^{+} 5.0, \mathrm{Ca}^{2+} 2.5, \mathrm{Mg}^{2+} 1.5, \mathrm{Cl}^{-} 147.8, \mathrm{HCO}_{3}^{-}\right.$

Table 1 Solution concentration, temperature and immersion time for sulfonation of polymers

\begin{tabular}{llll}
\hline Polymer & Solution & $\begin{array}{l}\text { Concentration } \\
(\text { vol\%) }\end{array}$ & $\begin{array}{l}\text { Temperature and immersion } \\
\text { time }\end{array}$ \\
\hline PET & $\mathrm{H}_{2} \mathrm{SO}_{4}$ & 50 & $40{ }^{\circ} \mathrm{C}, 24 \mathrm{~h}$ \\
Nylon 6 & $\mathrm{H}_{2} \mathrm{SO}_{4}$ & 10 & $40{ }^{\circ} \mathrm{C}, 24 \mathrm{~h}$ \\
EVOH & $\mathrm{H}_{2} \mathrm{SO}_{4}$ & 20 & $40{ }^{\circ} \mathrm{C}, 24 \mathrm{~h}$ \\
HMWPE & $\mathrm{ClSO}_{3} \mathrm{H}$ & 50 & $40{ }^{\circ} \mathrm{C}, 10 \mathrm{~min}$ \\
\hline
\end{tabular}


4.2, $\mathrm{HPO}_{4}^{2-} 1.0, \mathrm{SO}_{4}^{2-} 0.5 \mathrm{mM}$ ) nearly equal to those of the human blood plasma at $36.5{ }^{\circ} \mathrm{C}$ for different periods up to $7 \mathrm{~d}$. The SBF was prepared by dissolving reagent-grade chemicals of $\mathrm{NaCl}, \mathrm{NaHCO}_{3}, \mathrm{KCl}, \mathrm{K}_{2} \mathrm{PO}_{4} \cdot 3 \mathrm{H}_{2} \mathrm{O}$, $\mathrm{MgCl}_{2} \cdot 6 \mathrm{H}_{2} \mathrm{O}, \mathrm{CaCl}_{2}$ and $\mathrm{NaSO}_{4}$ into distilled water, and buffered at $\mathrm{pH} 7.40$ with tris-hydroxymethyl-aminomethane $\left(\left(\mathrm{CH}_{2} \mathrm{OH}\right)_{3} \mathrm{CNH}_{3}\right)$ and $1 \mathrm{M}$ hydrochloric acid at $36.5^{\circ} \mathrm{C}$. After soaking, the substrates were removed from $\mathrm{SBF}$, washed with distilled water and dried in a clean bench.

Analyses of surface and SBF

Surfaces of polymer substrates before and after the solution treatments were analyzed by field-emission scanning electron microscopy (FE-SEM: S-4700, Hitachi Ltd., Japan) attached with energy-dispersive electron X-ray spectroscopy (EDX: EMAX-7000, Horiba Ltd., Japan), thin film Xray diffraction (TF-XRD: RINT2500, Rigaku Co., Japan) and Fourier transform attenuated total reflectance infrared spectroscopy (FT-IR: Magna 860, Nicolet Co., USA).

Element concentrations of the SBF before and after soaking of the polymer substrates were measured using inductively coupled plasma atomic emission spectrometry (ICP: SPS-1500VR, Seiko Instruments Inc., Japan).

\section{Results}

\section{FT-IR and TF-XRD analyses}

Figures 1 to 4 show FT-IR spectra and TF-XRD patterns of the surfaces of different polymers, which were subjected to the sulfonation treatment, the subsequent $\mathrm{Ca}(\mathrm{OH})_{2}$ treatment and those subjected to soaking in SBF for 7 day after the sulfonation treatment, and those subjected to soaking in SBF for 7 day after the sulfonation and the $\mathrm{Ca}(\mathrm{OH}) 2$ treatments.

For PET no changes after sulfonation and $\mathrm{Ca}(\mathrm{OH})_{2}$ treatment were observed, and Nylon6 presented only sulfonic stretching band after the sulfonation (See the Figs. 1, 2). For HMWPE, hydration of polymer surfaces is evident after the detection of a wide $\mathrm{OH}$ stretching band (from 3500 to $3100 \mathrm{~cm}^{-1}$ ), involving both the presence of S-OH groups and absorbed water (See the Fig. 3). In the spectra for both polymers are observed reflection bands at 1200 and $1050 \mathrm{~cm}^{-1}$ that are attributed to the asymmetric and symmetric stretching modes of $-\mathrm{SO}_{3} \mathrm{H}$ groups [26]. When the HMWPE and EVOH were treated with $\mathrm{Ca}(\mathrm{OH})_{2}$, the intensity of the reflection bands associated with sulfonic groups decreased as it can be seen in FT-IR spectra (See the Figs. 3, 4). This decrease was more pronounced for the EVOH polymer.

It is worth noting that specimens soaked in SBF just after sulfonation, are not able to induce apatite nucleation. This fact points to a significant dependence of $\mathrm{Ca}(\mathrm{OH})_{2}$ treatment on the apatite-forming ability in the $\mathrm{SBF}$ of the $-\mathrm{SO}_{3} \mathrm{H}$ groups deposited on polymer specimens. However, in the case of PET and Nylon 6, even with the $\mathrm{Ca}(\mathrm{OH})_{2}$ treatment, these two polymers are not able to induce apatite nucleation. However, for Nylon 6 it was detected the presence of calcium sulphate after the sulfonation and $\mathrm{Ca}(\mathrm{OH})_{2}$ treatment as it is shown in the Fig. 2.
Fig. 1 FT-IR spectra and TFXRD patterns of the surfaces of PET, which were subjected to the sulfonation treatment $(\mathbf{A})$, to the subsequent $\mathrm{Ca}(\mathrm{OH})_{2}$ treatment $(\mathbf{B})$, to the soaking in SBF for 7 day after the sulfonation treatment $(\mathbf{C})$, and to the soaking in SBF for 7 day after the sulfonation and the $\mathrm{Ca}(\mathrm{OH})_{2}$ treatments $(\mathbf{D})$
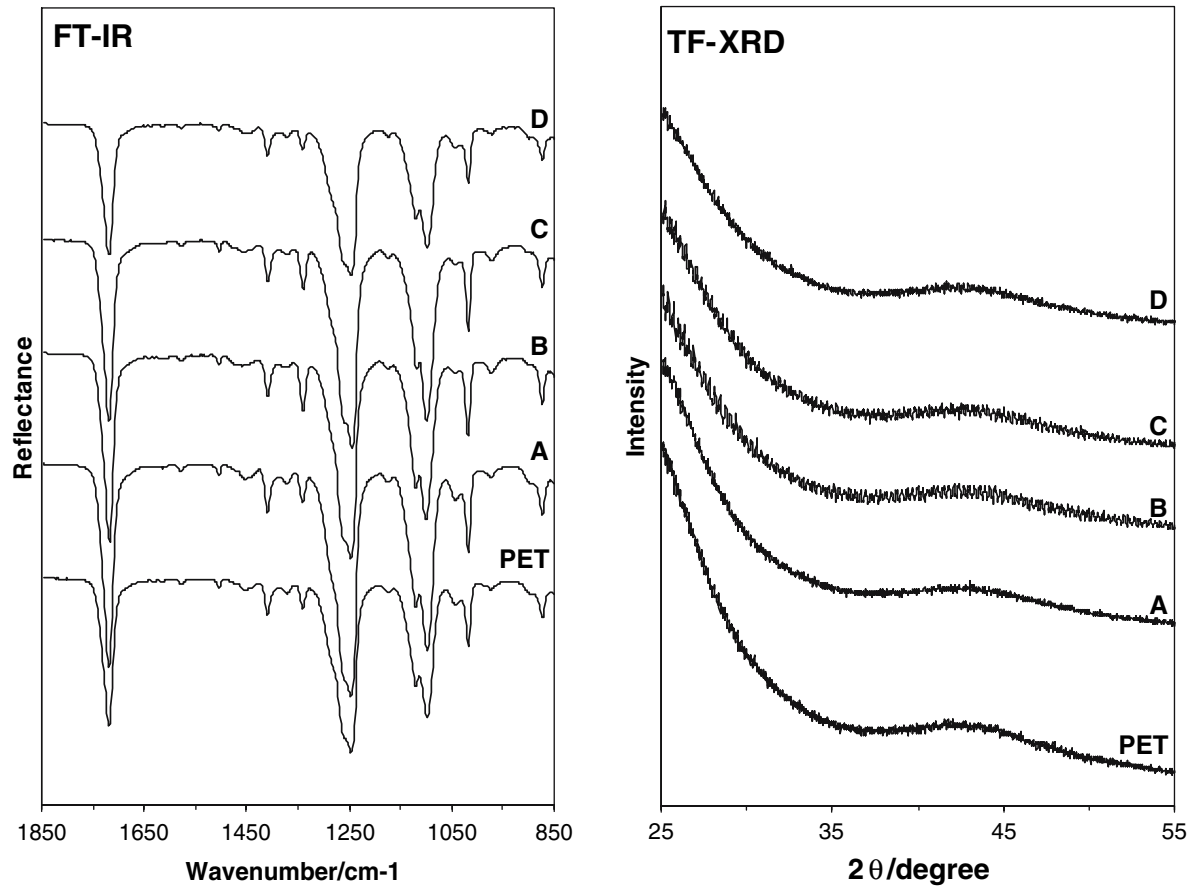
Fig. 2 FT-IR spectra and TFXRD patterns of the surfaces of Nylon 6, which were subjected to the sulfonation treatment $(\mathbf{A})$, to the subsequent $\mathrm{Ca}(\mathrm{OH})_{2}$ treatment (B), to the soaking in SBF for 7 day after the sulfonation treatment $(\mathbf{C})$, and to the soaking in SBF for 7 day after the sulfonation and the $\mathrm{Ca}(\mathrm{OH})_{2}$ treatments $(\mathbf{D})$
Fig. 3 FT-IR spectra and TFXRD patterns of the surfaces of HMWPE, which were subjected to the sulfonation treatment $(\mathbf{A})$, to the subsequent $\mathrm{Ca}(\mathrm{OH})_{2}$ treatment $(\mathbf{B})$, to the soaking in SBF for 7 day after the sulfonation treatment $(\mathbf{C})$, and to the soaking in SBF for 7 day after the sulfonation and the $\mathrm{Ca}(\mathrm{OH})_{2}$ treatments $(\mathbf{D})$
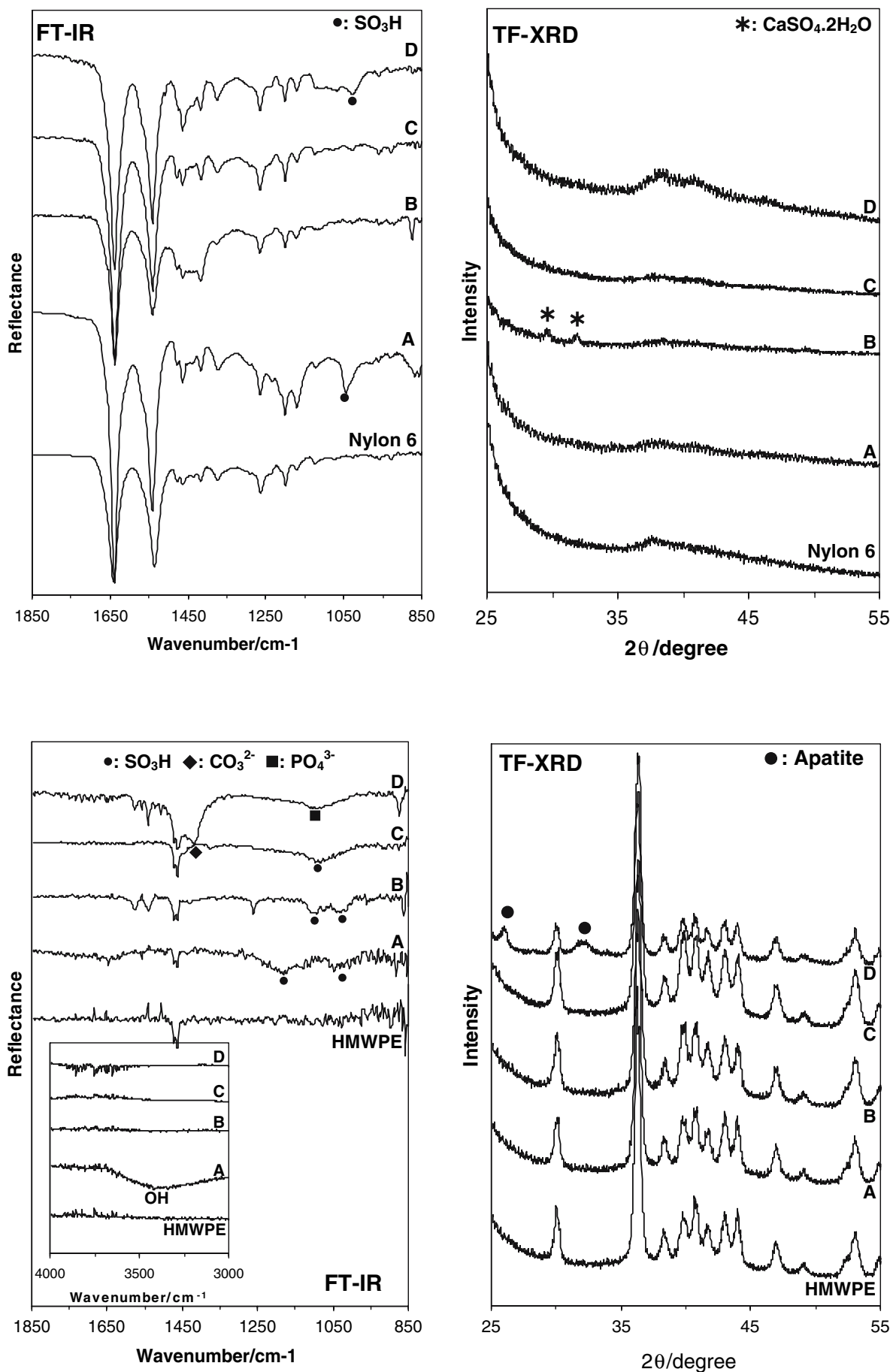

In the case of HMWPE and EVOH, the results were completely different after the $\mathrm{Ca}(\mathrm{OH})_{2}$ treatment, as it can be observed in the TF-XRD. For HMWPE, it can be observed that the structure of remains unaltered after sulfonation, showing the same reflections observed for untreated specimen even after the immersion in the calcium hydroxide solution (See the Fig. 3). On the other hand, EVOH specimens undergo several surface changes after sulfonation and $\mathrm{Ca}(\mathrm{OH})_{2}$ treatment that involve the nucleation of poorly-crystalline calcium sulfate $\left(\mathrm{CaSO}_{4} \cdot 2 \mathrm{H}_{2} \mathrm{O}\right.$, ASTM JCPDS 21-816), as it can be observed in Fig. 4. Moreover, TF-XRD patterns of the surface of both polymer specimens after soaking in SBF for several periods (using non-immersed samples as controls) show several diffraction maxima that can be assigned to an apatite-like phase (ASTM JCPDS 9-432). Intensities of detected maxima increase as the soaking time in SBF increases. 
Fig. 4 FT-IR spectra and TFXRD patterns of the surfaces of EVOH, which were subjected to the sulfonation treatment $(\mathbf{A})$, to the subsequent $\mathrm{Ca}(\mathrm{OH})_{2}$ treatment $(\mathbf{B})$, to the soaking in SBF for 7 day after the sulfonation treatment $(\mathbf{C})$, and to the soaking in SBF for 7 day after the sulfonation and the $\mathrm{Ca}(\mathrm{OH})_{2}$ treatments $(\mathbf{D})$
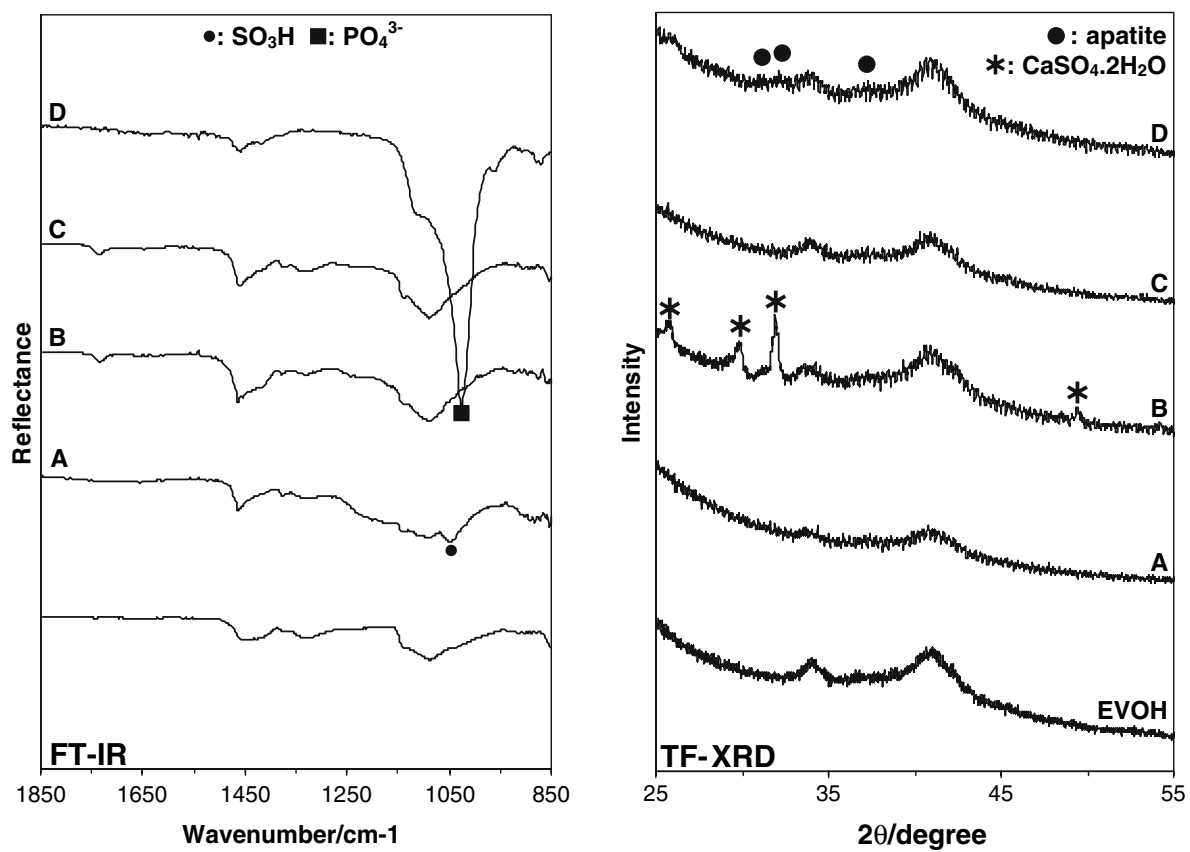

\section{SEM-EDX and ICP analyses}

All polymeric specimens soaked in SBF just after the sulfonation, are not able to induce the formation of an apatite layer on their surfaces. Figures 5 and 6 show the FE-SEM images of the HMWPE and EVOH specimens before and after sulfonation, $\mathrm{Ca}(\mathrm{OH})_{2}$ treatment and subsequent soaking in SBF for $7 \mathrm{~d}$. It is worth noting that after the sulfonation procedure there were not signals of any eventual degradation of the polymers. As it can be seen in Figs. 5 and 6, after the immersion in SBF a dense and uniform apatite layer is deposited on both specimens. For the HMWPE substrate, such apatite layer was detected only after 3 day of immersion in SBF. In the case of EVOH, 7 day in SBF was required to observe the formation of a dense apatite layer. Moreover, at higher magnifications it is evidenced a finer structure where needle-like crystals are agglomerated.

The EDX spectra of both sulfonated HMWPE and EVOH specimens show the sulfur (S) signal centered at $2.3 \mathrm{keV}$ (See the Figs. 5, 6). After the $\mathrm{Ca}(\mathrm{OH})_{2}$ treatment, in EDX spectra is observed a small signal ascribed to calcium (Ca), as well as $\mathrm{S}$ for both specimens that are in good agreement with the detection of calcium sulfate $\left(\mathrm{CaSO}_{4} \cdot 2 \mathrm{H}_{2} \mathrm{O}\right)$ in TF-XRD patterns (Fig. 4). After soaking in SBF for one day, a small signal ascribed to phosphorus $(\mathrm{P})$ was detected and the intensity of $\mathrm{S}$ band decreased. As the soaking time in SBF increased, the intensity of $\mathrm{Ca}$ and $\mathrm{P}$ signals significantly increased.

Figure 7 shows the concentrations of $\mathrm{Ca}$ and $\mathrm{P}$ in the SBF as a function of immersion time of HMWPE and EVOH specimens. After 1 day of soaking, a slight increase
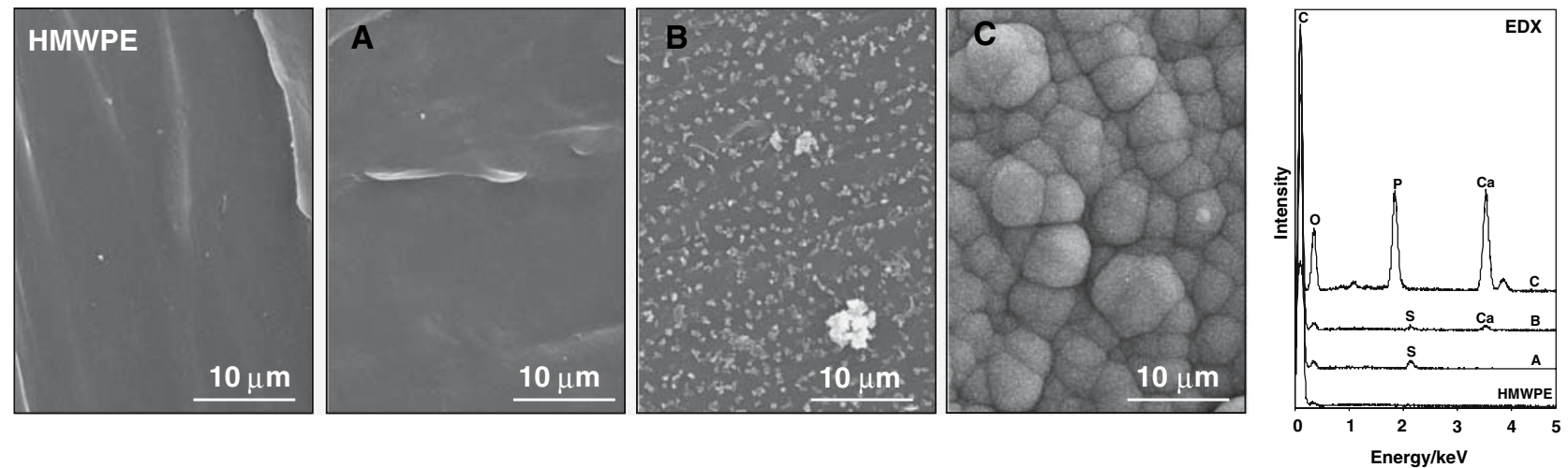

Fig. 5 SEM-EDX profiles of the surfaces of HMWPE, which were subjected to the sulfonation treatment $(\mathbf{A})$, to the subsequent $\mathrm{Ca}(\mathrm{OH})_{2}$ treatment $(\mathbf{B})$, to the soaking in SBF for 7 day after the sulfonation and the $\mathrm{Ca}(\mathrm{OH})_{2}$ treatments $(\mathbf{C})$ 

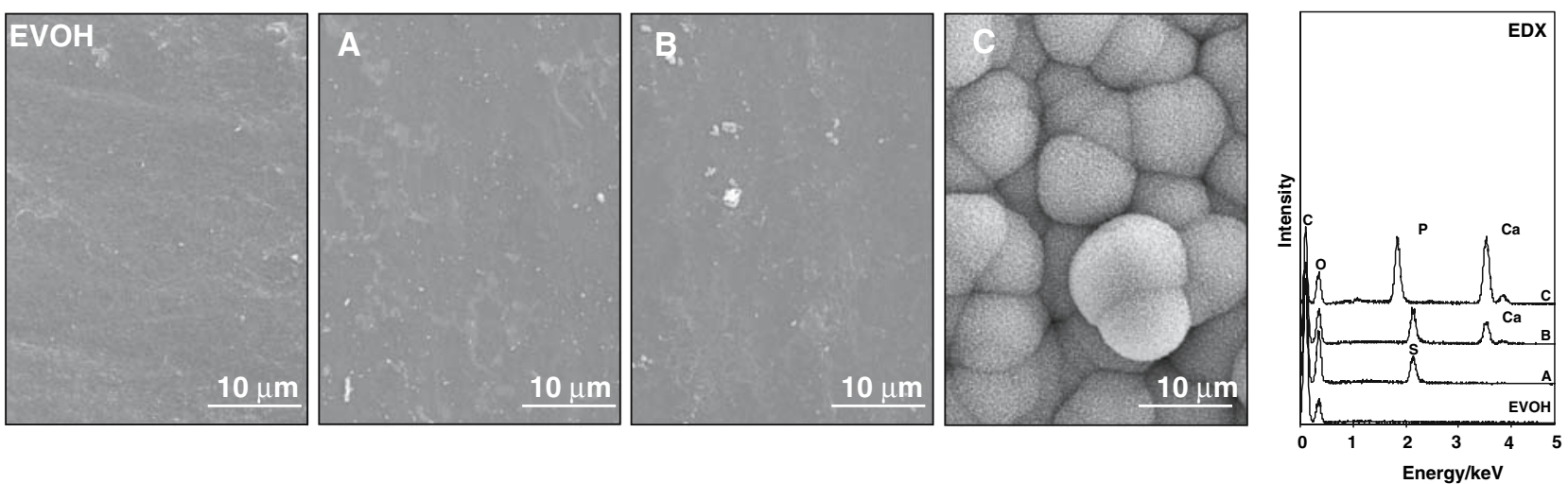

Fig. 6 SEM-EDX profiles of the surfaces of $\mathrm{EVOH}$, which were subjected to the sulfonation treatment $(\mathbf{A})$, to the subsequent $\mathrm{Ca}(\mathrm{OH})_{2}$ treatment (B), to the soaking in SBF for 7 day after the sulfonation and the $\mathrm{Ca}(\mathrm{OH})_{2}$ treatments $(\mathbf{C})$

in the amount of $\mathrm{Ca}$ in the $\mathrm{SBF}$ can be noticed, which is attributed to the release of $\mathrm{Ca}^{2+}$ ions from the surface to the $\mathrm{SBF}$. As the immersion time increases, $\mathrm{Ca}$ and $\mathrm{P}$ concentrations decreased gradually probably due to the apatite formation by consuming the calcium and phosphate ions in the fluid.

\section{Discussion}

It is clear from the results described above that sulfonic ($\mathrm{SO}_{3} \mathrm{H}$ ) groups were incorporated onto the surface of HMWPE and EVOH through sulfonation and stabilized by soaking in a calcium hydroxide saturated solution. Thus surface modified samples are able to form a dense and uniform apatite layer after soaking up to seven days in simulated body fluid.

As well-known, sulfonation is a common procedure in material chemistry that can be defined as a substitution reaction that yields $-\mathrm{SO}_{3} \mathrm{H}$ groups on an organic compound via chemical bond to carbon or, less frequently, to a nitrogen atom of the organic compound [27].

When chlorosulfonic acid is used as reagent, the $-\mathrm{SO}_{3} \mathrm{H}$ groups are more extensively incorporated on the surface, since chlorine is a better leaving group and favors higher reactivity at the described conditions. Nevertheless, the surface reactivity of $\mathrm{EVOH}$ is larger and the use of strong sulfonating agents induces surface degradation and, eventually, specimen dissolution. Therefore, for the more chemically active polymers, such as $\mathrm{EVOH}$, sulfonation is carried out using diluted $\mathrm{H}_{2} \mathrm{SO}_{4}$ in order to modify the outer surface layer. Also, the sulfonation rate is enhanced for EVOH since the highly hydroxylated surface of this polymer [27].

In the case of PET, the amount of hydrophilic functionalities in the polymer surface has to be increased prior sulfonation. It is well-known that modification of PET in- volves chain cleavage leading new chain ends in the polymer surface and, also, causing degradation of polymer specimens. Reaction conditions have to be tuned to optimize the concentration of functional groups and minimize degradation. In the present study, all tested conditions, yield incorporation of $-\mathrm{SO}_{3} \mathrm{H}$ groups in a very low concentration in specimen surface and, also material degradation, which makes these specimens unuseful for the desired applications. Similar features are found for Nylon 6 specimens, sulfonation process allows the incorporation of $-\mathrm{SO}_{3} \mathrm{H}$ groups in very low concentrations together with the wearing down of surface layer on polymer specimens. The obtained results also confirm that the incorporation of $\mathrm{SO}_{3} \mathrm{H}$ groups onto HMWPE and EVOH specimens and their stabilization by immersion in a $\mathrm{Ca}(\mathrm{OH})_{2}$ saturated solution leads to the formation of a dense and uniform apatite layer after soaking in SBF for several periods. Moreover, as it can be observed after TF-XRD and FT-IR measurements, sulfonated specimens without calcium treatment are not able to form apatite on their surface in SBF even after $7 \mathrm{~d}$. It is speculated that the apatite forming ability induced by this functional group was significantly depends on the $\mathrm{Ca}(\mathrm{OH})_{2}$ treatment.

It has been demonstrated that the apatite formation is enhanced when $\mathrm{Ca}$ and/or $\mathrm{P}$ concentrations as well as $\mathrm{pH}$ in the SBF are increased [28]. When the sulfonated samples were soaking in $\mathrm{Ca}(\mathrm{OH})_{2}$ saturated solutions, it is expected that the $-\mathrm{SO}_{3} \mathrm{H}$ groups become negatively charged and interact with the positively charged $\mathrm{Ca}^{2+}$ from the $\mathrm{Ca}(\mathrm{OH})_{2}$ solution, as it is proposed in Fig. 8.

In the case of $\mathrm{EVOH}$ specimens, the formation of $\mathrm{Ca}$ $\mathrm{SO}_{4} \cdot 2 \mathrm{H}_{2} \mathrm{O}$ phase was observed, which may be related to the hydroxyl groups belonging to the polymer organic skeleton, near the surface of specimens (See the Fig. 4). As a result, when specimens are soaked in SBF, a bonelike apatite layer is formed on both specimens, as it can be observed in FE-SEM images for specimens (Figs. 5, 6). 

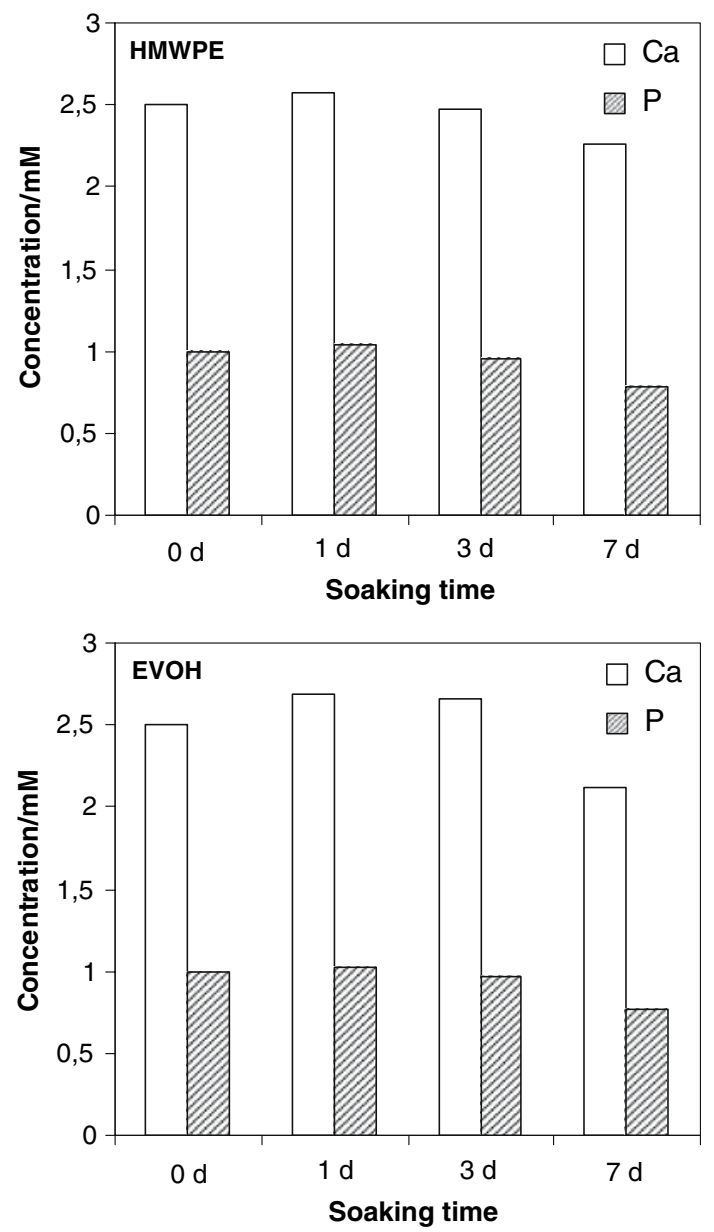

Fig. 7 Changes in $\mathrm{Ca}$ and $\mathrm{P}$ concentration of the SBF with soaking time of the HMWPE and EVOH which were subjected to the sulfonation and subsequent $\mathrm{Ca}(\mathrm{OH})_{2}$ treatments

This is attributed to the release of the $\mathrm{Ca}^{2+}$ ions from the surface of the specimens through ion exchange with the $\mathrm{H}_{3} \mathrm{O}^{+}$ions in SBF, as confirmed after the ICP measurements. Therefore, the ionic activity product of surrounding fluid with respect to apatite is increased, accelerating apatite nucleation on the calcium-stabilized $-\mathrm{SO}_{3} \mathrm{H}$ groups.
Once apatite nuclei are formed, they can spontaneously grow into a uniform layer by consuming the calcium and phosphate ions from the SBF [29].

The apatite layer deposited on both the materials shows a good adhesion, since it is not peeled off from the surface of the specimens by means of a simple preliminary tapedetaching test. This can be attributed to the formation of chemical bonds between the polymer and the sulfonic groups, improving the linkage with the deposited apatite layer.

Finally, it is worth to state the efficacy for bonelike apatite nucleation of the $-\mathrm{SO}_{3} \mathrm{H}$ groups attached to different polymeric surfaces, and combined with the $\mathrm{Ca}^{2+}$ ions. This feature confirms that proposed sulfonation reactions just transform the chemical composition and structure of the outer surface layer, remaining unaltered the substrate bulk properties. If such surface modification is applied to three-dimensional scaffolds with a similar structure to that of the collagen fibers in natural bone, it is possible to prepare apatite-polymer composites with analogous structure and mechanical properties to those of natural bone. These kinds of materials are very useful for the treatments of bone diseases and replacement, as well as for tissue-engineering scaffolds.

\section{Conclusions}

Sulfonic $\left(-\mathrm{SO}_{3} \mathrm{H}\right)$ groups were incorporated onto the surface of HMWPE and EVOH through sulfonation and stabilization by soaking in a calcium hydroxide saturated solution. The surface modified samples were able to form a dense and uniform apatite layer after soaking up to seven days in simulated body fluid. Incorporation of calcium ions into the sulfonated specimens is a pre-requisite for the apatite nucleation, since the release of these ions accelerates the apatite formation in the SBF environment. The proposed methods are believed promising for the production of polymer-based bioactive materials with better biocompatibility and a bone-bonding ability.
Fig. 8 Mechanism of sulfonation on HMWPE and $\mathrm{EVOH}$ and stabilization of the sulfonic groups by binding calcium ions

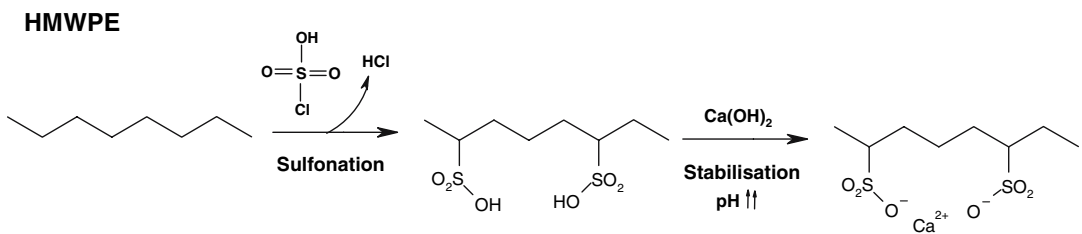

EVOH

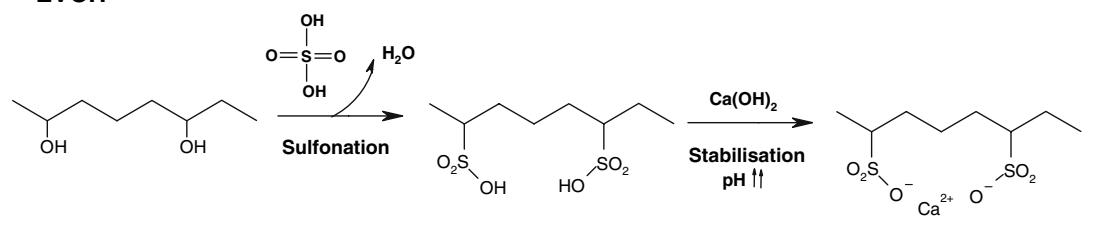


Acknowledgments I. B. Leonor thanks the Portuguese Foundation for Science and Technology for providing her a $\mathrm{PhD}$ scholarship (SFRH/BD/9031/2002). This work was partially supported by FCT Foundation for Science and Technology, through funds from the POCTI and/or FEDER programmes.

\section{References}

1. L. L. HENCH, R. J. SPLINTER, W. C. ALLEN and T. K. GREENLEE, J. Biomed. Mater. Res. Symp. 2 (1971) 117

2. M. JARCHO, J. L. KAY, R. H. GUMAER and H. P. DROBECK, J. Bioeng. 1 (1977) 79

3. H. AOKI, K. KATO, M. OGISO and T. TABATA, J. Dent. Outlook. 49 (1977) 567

4. T. KOKUBO, M. SHIGEMATSU, Y. NAGASHIMA, M. TASHIRO, T. NAKAMURA, T YAMAMURO and S. HIGASHI, Bull. Inst. Chem. Res. 60 (1982) 260

5. J. WILSON, A. YLI-URPO and H. RISTO-PEKKA, An Introduction to Bioceramics (World Scientific, Singapore, 1993) p. 63

6. E. C. SHORES and R. E. HOLMES, An Introduction to Bioceramics (World Scientific, Singapore, 1993) p. 181

7. T. YAMAMURO, An Introduction to Bioceramics (World Scientific, Singapore, 1993) p. 89

8. M. NEO, S. KOTANI, T. NAKAMURA, T. YAMAMURO, C. OHTSUKI, T. KOKUBO and T. YAMAMURO, J. Biomed. Mater. Res. 26 (1992) 1419

9. M. NEO, T. NAKAMURA, C. OHTSUKI, T. KOKUBO and T. YAMAMURO, J. Biomed. Mater. Res. 27 (1993) 999

10. T. KITSUGI, T. NAKAMURA, T. YAMAMURA, T. KOKUBO, T. SHIBUYA and M. TAKAGI, J. Biomed. Mater. Res. 21 (1987) 1255

11. T. KOKUBO, S. ITO, Z. T. HUANG, T. HAYASHI, S. SAKKA, T. KITSUGI and T. YAMAMURA, J. Biomed. Mater. Res. 24 (1990) 331

12. T. KOKUBO, J. Non-Cryst. Sol. 120 (1990) 138

13. T. HIMENO, M. KAWASHITA, H.-M. KIM, T. KOKUBO and T. NAKAMURA, in Bioceramics 14, edited by S. BROWN, I. R.
CLARKE and P. WILLIAMS, (Trans Tech Publications, Switzerland, 2001) p. 641

14. H.-M. KIM, T. HIMENO, T. KOKUBO and T. NAKAMURA, Biomaterials 26 (2005) 4366

15. H.-M. KIM, T. HIMENO, M. KAWASHITA, J. H. LEE, T. KOKUBO and T. NAKAMURA, J. Biomed. Mater. Res. 67A (2003) 1305

16. T. KOKUBO, F. MIYAJI, H.-M. KIM and T. NAKAMURA, $J$. Am. Ceram. Soc. 79 (1996) 1127

17. H.-M. KIM, F. MIYAJI, T. KOKUBO and T. NAKAMURA, $J$. Biomed. Mater. Res. 32 (1996) 409

18. A. OYANE, M. KAWASHITA, K. NAKANISHI, T. KOKUBO, M. MINODA, T. MIYAMOTO and T. NAKAMURA, Biomaterials 24 (2003) 1729.

19. A. OYANE, M. KAWASHITA, T. KOKUBO, M. MINODA, T. MIYAMOTO and T. NAKAMURA, J. Ceram. Soc. Japan. 110 (2002) 248

20. S. YAMASHITA, S. NAGATA and K. TAKAKURA, Kobunshi Ronbunshu 36 (1979) 257

21. F. R. PU, R. L. WILliAMS, T. K. MARKKULA and J. A. HUNT, Biomaterials 23 (2002) 2411

22. S. RAMAKRISHNA, J. MAYER, E. WINTERMANTEL and K. W. LEONG, Composites Sci. Technol. 61 (2001) 1189

23. K. HATTORI, N. TOMITA, T. YOSHIKAWA and Y. TAKAKURA, Mater. Sci. Eng: C. 17 (2001) 27

24. B. L. SEAL, T. C. OTERO and A. PANITCH, Mater. Sci. Eng. R34 (2001) 147

25. T. KOKUBO, H. KUSHITANI, S. SAKKA, T. KITSUGI and T. YAMAMURO, J. Biomed. Mater. Res. 24 (1990) 721

26. G. SOCRATES, Infrared Characteristic Group Frequencies (John Wiley Sons, Chichester, 1998)

27. F. KUCERA and J. JANCAR, Polym. Eng. Sci. 38 (1998) 783

28. P. LI, C. OHTSUKI, T. KOKUBO, K. NAKANISHI, N. SOGA, T. NAKAMURA and T. YAMAMURO, J. Appl. Biomat. 4 (1993) 221

29. H.-M. KIM, J. Ceram. Soc. Japan 109 (2001) S49 